\title{
Risk Factors and Outcome of Neonates Born through Meconium Stained Amniotic Fluid in a Tertiary Hospital of Nepal
}

\author{
Gurubacharya $\mathrm{SM}^{1}$, Rajbhandari $\mathrm{S}^{2}$, Gurung $\mathrm{R}^{3}$, Rai $\mathrm{A}^{4}$, Mishra $\mathrm{M}^{5}$, Sharma $\mathrm{KR}^{6}$, Aryal $\mathrm{DR}^{7}$
}

\begin{abstract}
Introduction: The incidence of meconium aspiration syndrome is still high in the developing world contributing significantly to the neonatal mortality. The study was aimed to know the risk factors contributing to meconium aspiration syndrome and neonatal outcome in a tertiary government hospital of the country. Materials and Methods: It was a hospital based cross sectional study done over a period of three months. All live newborns born through meconium stained liquor were enrolled and all the details regarding mother, neonate were recorded. Odd's ratio and bivariate analysis was done to assess the risk factors for meconium aspiration syndrome. Result: Out of all the deliveries $14.6 \%$ were meconium stained amniotic fluid and meconium aspiration syndrome developed in $6.6 \%$ of the neonates. Low Apgar score and premature rupture of membranes was significantly associated with the risk of occurrence of meconium aspiration syndrome. Neonates who developed meconium aspiration syndrome had mortality of $11.3 \%$. Conclusion: Perinatal asphyxia and premature rupture of membranes were significantly associated with the development of meconium aspiration syndrome and neonates who developed meconium aspiration syndrome had high mortality.
\end{abstract}

Key words: Asphyxia, meconium, neonate

\section{Introduction}

$\mathrm{M}$ econium Aspiration Syndrome (MAS) is an important cause of morbidity and mortality among newborns in the developing world. Meconium stained amniotic fluid (MSAF) occurs in approximately $13 \%$ of all live births ${ }^{1}$. Presence of meconium is a sign of fetal distress warranting immediate evaluation and action. It can lead to MAS. MAS is defined as respiratory distress in an infant born through MSAF whose symptoms otherwise cannot be explained ${ }^{2}$. It leads to poor lung compliance, hypoxemia leading to respiratory distress with complications like respiratory failure, pulmonary air leaks and persistent pulmonary hypertension of the newborn. Onethird of infants require intubation and mechanical ventilation ${ }^{3,4}$ and newer neonatal therapies like high frequency ventilation, inhaled Nitric Oxide and surfacant administration ${ }^{5,6}$.The incidence of MAS, morbidity and mortality varies among countries. According to western data there has been a reduction in the incidence of MAS in
'Dr Simmi Misra Gurubacharya, Chief Registrar, Associate Professor, ${ }^{2}$ Dr Shistata Rajbhandari, Medical Officer, ${ }^{3}$ Dr Roshma Gurung, Medical Officer, ${ }^{4} \mathrm{Dr}$ Asha Rai, Medical Officer, ${ }^{5} \mathrm{Dr}$ Megha Mishra, Medical Officer, ${ }^{6} \mathrm{Dr}$ Kamal Raj Sharma, Senior Consultant, 'Dr Dhana Raj Aryal, Chief Consultant, Head of The Department. All from the department of Neonatology, Paropakar Maternity and Women's Hospital, Kathmandu, Nepal.

\author{
Address for correspondence: \\ Dr. Simmi M Gurubacharya \\ Paropakar Maternity and Women's Hospital \\ Department of Neonatology, \\ Kathmandu, Nepal \\ Phone No.: +9779841560911 \\ Email: drsimmimg@gmail.com
}

\section{How to cite}

Gurubacharya SM, Rajbhandari S, Gurung R, Rai A, Mishra M, Sharma KR, Aryal DR. Risk Factors and Outcome of Neonates Born through Meconium Stained Amniotic Fluid in a Tertiary Hospital of Nepal. J Nepal Paediatr Soc 2015;35(1):44-48.

doi: http://dx.doi.org/10.3126/jnps.v35i1.12171

This work is licensed under a Creative Commons Attribution 3.0 License.

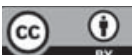

the past decade due to advances in perinatal care ${ }^{7}$. This has been attributed to better obstetric practices. There is paucity of data regarding the neonatal outcome of babies born through MSAF in Nepal. This study is aimed to assess the perinatal attributes, mortality and morbidity associated with babies born through MSAF. The study would reflect the prenatal and postnatal care of babies delivered through MSAF and the improvement as required in the perinatal health services so that adverse outcome is prevented as well as minimized especially at the regional level II/III perinatal centre. 


\section{Materials and Methods}

All live babies born though MSAF over duration of three months from April 2010 to June 2010 were enrolled. This was a cross-sectional study. To assess the risk factors related with MSAF deliveries and MAS all the details regarding mode of delivery, APGAR score (AS), birth weight, fetal distress, birth asphyxia, maternal age, any maternal illness and parity, time of rupture of membranes, gestational age, chest radiograph findings, clinical course, outcome and mechanical ventilation (MV) as needed were recorded and evaluated. Newborns with gross congenital anomalies were excluded. Risk estimation analysis for MAS was done by calculating Odd's Ratio (OR) and Bivariate Analysis.

\section{Results}

There were total 5641 live births over a period of three months. Out of these deliveries 824 babies were born through MSAF which estimates to be $14.6 \%$. Owing to the lack of complete data 27 babies were excluded. Among 797 babies born through MSAF, 53 developed MAS i.e.6.6\%. Table 1 show different variables studied as risk factors for MAS. Among all the variables APGAR score at 1 minute and 5 minute, premature rupture of membranes (PROM) and need of mechanical ventilation were significant variables associated with increased risk of MAS in the babies born through MSAF by Chisquare test. Table 2 shows the bivariate analysis further done that revealed APGAR score at 1 minute and 5 minute, need of resuscitation and PROM as significant factors contributing to increased incidence of MAS. The clinical outcome is shown in Table 3. Neonates born through meconium stained liquor were diagnosed and categorized as shown in Table 4. Among the category of others, conditions like congenital heart diseases, intrauterine pneumonia, neonatal depression and suspected case of spinal muscular atrophy were present.

\section{Discussion}

In the study MSAF deliveries were $14.6 \%$ and out of all the neonates born through MSAF, $6.6 \%$ developed MAS. The occurrence of MSAF varied from $7.9 \%$ to $18 \%^{8,9}, 10,12$ in other studies. The study done by Bhat RY ${ }^{11}$ showed MAS occurred in $11.3 \%$ of babies born through MSAF while in other studies it varied from $1 \%$ to $38.5 \%^{8,9,10,12,13}$. Seventeen percent of the babies among MAS group required mechanical ventilation and three newborns were referred due to the ventilators being occupied. Among all the neonates born through MSAF 41.8\% were born through normal vaginal delivery, $49.4 \%$ through caesarean section and $8.7 \%$ by assisted delivery, vacuum being the commonest method. Out of all the babies who developed MAS 39.6\% were born through normal vaginal delivery, $47.1 \%$ born through caesarean section and $13.2 \%$ through assisted vaginal delivery. Mode of delivery was not found to be a significant risk factor for MAS. Some of the studies ${ }^{12}$ do not reflect caesarean delivery as the significant risk factor while other studies showed it as the significant risk factor for $\mathrm{MAS}^{7,14}$. $82 \%$ of the mother belonged to the age group of 20 to 34 years and those mothers who developed MAS $83 \%$ were in the age group of 20 to 34 years. Age of the mother, parity and birth weight of babies did not show significant association with MAS similar to other authors ${ }^{12,14}$ while few studies showed the association for the parity ${ }^{9,15}$. Although there was increased incidence of MSAF and MAS in the post dated group between 40 to 42 weeks but the gestation was not significantly associated with increased incidence of MAS as seen in other studies ${ }^{7,14}$. The number of post term pregnancy was quite less as compared to other gestational groups probably our hospital being a tertiary hospital and intervention is done timely before the pregnancy could reach post term. Fischer $\mathrm{C}$ et $\mathrm{al}^{14}$ found in their study gestational age as main risk factor of MAS but the incidence of MAS in neonates born through MSAF did not depend on gestational age.

Bivariate analysis showed APGAR score at 1 minute, 5 minute, PROM and need of resuscitation as significant factors contributing to increased incidence of MAS. Peter $A D^{7}$ found in Australian live births a very strong association with a 5 minute APGAR score $<7$ with an overall Odd's ratio of 52. Similar observation was made by Bhat RY, Liu WF in their study where they found APGAR score at 1 minute and 3 minutes as significant but they took APGAR score value at 1 minute as 6 and at 3 minute as 7 respectively. In another study $^{12}$ APGAR score at 5 minute < or $=5$ was found to be significant. Meydlani MM et al ${ }^{15}$ found APGAR score $<$ or $=6$ at 5 minute $(\mathrm{RR}=3.8,95 \% \mathrm{Cl}=1.7-8.4)$ as significant risk factor for MAS. Similarly others ${ }^{14,16}$ have shown low APGAR score as main risk factor for MAS reflecting perinatal asphyxia as a significant risk factor. Those babies requiring resuscitation had significant association with MAS and so are reflected by low APGAR score at 1 and 3 minute. Low APGAR score and need of resuscitation signify the need of improvement in antenatal care and preventing perinatal asphyxia to prevent the morbidity and mortality associated with MAS. $30 \%$ to $50 \%$ cases of MAS may require mechanical ventilation or continuous positive airway pressure ${ }^{17}$. PROM was also a significant risk for the development of MAS. In the study done by Bhaskar SH et $\mathrm{al}^{9}$ the incidence of MAS was significantly higher in mothers 
with PROM. This observation reflects that monitoring and timely intervention is needed when there is history of ruptured membranes to prevent MAS. In our study mortality among those who developed MAS was $11.3 \%$. The mortality reported in other studies ${ }^{7,11,13,18}$ varied from $2.5 \%$ to $33 \%$. The mortality was high especially when compared to western data ${ }^{7}$. In a tertiary hospital where many obstetric cases were referred cases, along with the setting of limited resources, inappropriate ratio of patient to health personnel, and limited availability of technology, decreasing morbidity and mortality is a big challenge.

Table 1: Variables and their association with MAS among neonates born through MSAF

\begin{tabular}{|c|c|c|c|c|c|}
\hline Variables & & No MAS & MAS & Total & $p$-value \\
\hline & $<20$ & 108 & 7 & 115 & \\
\hline Age Group & $20-34$ & 613 & 44 & 657 & 0.898 \\
\hline (years) & $>34$ & 23 & 2 & 25 & \\
\hline \multirow[t]{2}{*}{ Sex } & 1 & 407 & 29 & 436 & 0.999 \\
\hline & 2 & 337 & 24 & 361 & \\
\hline Birth weight & $<2500$ & 53 & 7 & 60 & 0.105 \\
\hline (grams) & $>=2500$ & 691 & 46 & 737 & \\
\hline \multirow[t]{2}{*}{ AS 1 minute } & $<=3$ & 38 & 27 & 65 & $<0.001$ \\
\hline & $>3$ & 706 & 26 & 732 & \\
\hline \multirow[t]{3}{*}{ AS 5 minute } & $<=3$ & 13 & 7 & 20 & $<0.001$ \\
\hline & $>3$ & 731 & 46 & 777 & \\
\hline & Normal & 311 & 21 & 332 & \\
\hline \multirow[t]{2}{*}{ Mode of delivery } & Vacuum & 65 & 7 & 72 & 0.548 \\
\hline & Caesarean & 368 & 25 & 393 & \\
\hline \multirow[t]{3}{*}{ Asphyxia } & Yes & 37 & 33 & 70 & $<0.001$ \\
\hline & No & 707 & 20 & 727 & \\
\hline & MSAF & 731 & 53 & 784 & \\
\hline \multirow[t]{3}{*}{ Fetal distress } & $\begin{array}{l}\text { MSAF with } \\
\text { tachycardia }\end{array}$ & 1 & 0 & 1 & 0.815 \\
\hline & $\begin{array}{l}\text { MSAF with } \\
\text { bradycardia }\end{array}$ & 11 & 0 & 11 & \\
\hline & $\begin{array}{c}\text { Decreased fetal } \\
\text { movements }\end{array}$ & 1 & 0 & 1 & \\
\hline \multirow[t]{2}{*}{ Resuscitation } & Yes & 30 & 28 & 58 & $<0.001$ \\
\hline & No & 714 & 25 & 739 & \\
\hline \multirow[t]{2}{*}{ PROM } & Yes & 13 & 4 & 17 & 0.005 \\
\hline & No & 731 & 49 & 780 & \\
\hline \multirow[t]{3}{*}{ Maternal illness } & Yes & 34 & 5 & 39 & 0.113 \\
\hline & No & 710 & 48 & 758 & \\
\hline & Primi & 448 & 33 & 480 & \multirow{2}{*}{0.225} \\
\hline \multirow[t]{2}{*}{ Parity } & *G2-G4 & 279 & 16 & 293 & \\
\hline & >G4 & 18 & 3 & 20 & \\
\hline Gestational age & $>42$ & 39 & 2 & 41 & \\
\hline \multirow[t]{2}{*}{ (weeks) } & $37-40$ & 220 & 13 & 233 & 0.724 \\
\hline & $40-42$ & 429 & 32 & 461 & \\
\hline \multirow[t]{2}{*}{ MV needed } & Yes & 2 & 9 & 11 & $<0.001$ \\
\hline & No & 742 & 44 & 786 & \\
\hline
\end{tabular}

*AS- APGAR score, G- Gravidarum, MSAF- Meconium stained amniotic fluid, MV- Mechanical ventilation 
Table 2: Risk Factors with increased incidence of MAS by Bivariate analysis

\begin{tabular}{|c|c|c|c|c|}
\hline & p-value & OR & $\mathbf{9 5 . 0 \% ~ C . I ~ f o r ~ O R ~}$ & Upper \\
\hline & & & 10.28 & 36.22 \\
\hline AS 1 minute & $<0.001$ & 19.29 & 3.26 & 22.48 \\
\hline AS 5 minute & $<0.001$ & 8.56 & 13.90 & 51.13 \\
\hline Resuscitation & $<0.001$ & 26.66 & 1.44 & 14.60 \\
\hline
\end{tabular}

*AS- APGAR score, PROM- Premature rupture of membrane

Table 3: Outcome of Neonates born through Meconium Stained Amniotic Fluid

\begin{tabular}{|c|c|c|c|}
\hline Clinical outcome & No MAS & MAS & Total \\
\hline Well baby & 693 & 0 & 693 \\
\hline Improved \& discharged & 45 & 47 & 92 \\
\hline Expired & 3 & 6 & 3 \\
\hline Referred & 3 & 0 & $\mathbf{7 9 7}$ \\
\hline Total & $\mathbf{7 4 4}$ & $\mathbf{5 3}$ & 9 \\
\hline
\end{tabular}

Table 4: Final Diagnosis of Neonates born through Meconium Stained Amniotic Fluid

\begin{tabular}{|l|c|c|}
\hline Outcome & Frequency & Percent \\
\hline MAS & 20 & 2.50 \\
\hline Perinatal Asphyxia & 14 & 1.76 \\
\hline Perinatal Asphyxia with MAS & 32 & 4.02 \\
\hline MAS with Sepsis & 1 & 0.12 \\
\hline Septicemia & 1 & 0.12 \\
\hline $\begin{array}{l}\text { Born through MSAF without any } \\
\text { complications }\end{array}$ & 718 & 90.1 \\
\hline Others & 11 & 1.38 \\
\hline Total & $\mathbf{7 9 7}$ & $\mathbf{1 0 0}$ \\
\hline
\end{tabular}

\section{Conclusion}

Among all the risk factors evaluated perinatal asphyxia and PROM were identified as significant in development of MAS in the neonates born through MSAF. The mortality is also high reflecting the need of improvement in the management of neonatal care at the tertiary level especially in the hospital where the number of high risk deliveries is more. Preventing perinatal asphyxia through appropriate monitoring and timely delivery will be the main key to prevent MAS. When history of PROM is present timely management is needed to prevent MAS and its sequelae as shown by the study.

Acknowledgements: Nil

Funding: None

Conflict of Interest: None

Permission from IRB: Yes

\section{References}

1. Walsh MC, Fanaroff JM. Meconium stained fluid: approach to the mother and the baby. Clin Perinatol 2007;34(4):653-55.

2. Fanaroff AA. Meconium aspiration syndrome: historical aspects. J Perinatol 2008;28:S3-S7.

3. Coltart TM, Byrne DL, Bates SA. Meconium Aspiration Syndrome: a 6-year retrospective study. Br J Obstet Gynaecol 1989;96:411-14.

4. Wiswell TE, Tuggle JM, Turner BS. Meconium aspiration syndrome: have we made a difference? Pediatrics 1990;85:715-21.

5. Bhutani VK, Chima R, Sivieri EM. Innovative neonatal ventilation and meconium aspiration syndrome. Indian J Pediatr 2003;70:421-27.

6. Wiswell TE. Advances in the treatment of the meconium aspiration syndrome. Acta Paediatr 2001;90:S28-30. 
7. Dargaville PA, Copnell Beverley. The Epidemiology of Meconium Aspiration Syndrome: Incidence, Risk Factors, Therapies and Outcome. Pediatrics 2006;117:1712-721.

8. Liu WF, Harrington T. Delivery room risk factors for meconium aspiration syndrome. Am J Perinatol 2002;19(7):367-78.

9. Bhaskar SH, Karthikeyan G, Bhat BV, Bhatia BD. Antenatal Risk Factors and Neonatal Outcome in Meconium Aspiration Syndrome: Indian J Maternal Child Health 1997;8(1):9-12.

10. Hernandez C, Little BB, Dax JS, Gilstrap LC, Rosenfield CR. Prediction of the severity of meconium aspiration syndrome. Am J Obstet Gynecol 1993;169:61-70.

11. Bhat RY, Rao A. Meconium-stained amniotic fluid and meconium aspiration syndrome: a prospective study. Ann Trop Paediatr 2008;28(3):199-203.

12. Khazardoost S, Hantoushzadeh S, Khooshideh M, Borna S. Risk Factors for meconium aspiration in meconium stained amniotic fluid. J Obstet Gynaecol 2007;27(6):577-79.
13. Malik AS, Hillman D. Meconium aspiration syndrome and neonatal outcome in a developing country. Ann Trop Paediatr 1994;14(1):47-51.

14. Fischer C, Rybakowski C, Ferdynus C, Sagot P, Gouyyon JB. A Population- Based Study of Meconium Aspiration Syndrome in Neonates born between 37 and 43 weeks of Gestation. Int J Pediatr 2012; 2012: 321-545.

15. Meydlani MM, Dilbaz b, Calistan E, Dilbaz S, Haberal A. Risk factors for meconium aspiration syndrome in infants born through thick meconium. Int J Gynaecol Obstet 2001;72:9-15.

16. Bhutani VK. Developing a systems approach to prevent meconium aspiration syndrome: lessons learned from multinational studies. J Perinatol 2008;28:S30-S35.

17. Goldsmith JP. Continous positive airway pressure and conventional mechanical ventilation in the treatment of meconium aspiration syndrome. J Perinatol 2008;28:S49-55.

18. Velaphi S, Van Kwawegen A. Meconium aspiration syndrome requiring assisted ventilation: perspective in a setting with limited resources. J Perinatol 2008;28:S36-42. 